\title{
A preferência de Yahweh foi pelos detentores do poder (Esd 9-10) ou pelos humilhados (Rute)?: uma glosa que quis mudar tudo (Rt 4,17d-22)
}

\author{
Was Yahweh's preference for the holders of power (Esd \\ 9-10) or for he humiliated (Ruth)?: a glossy that wanted to \\ change everything (rt 4,17d-22)
}

JOEL ANTÔNIO FERREIRA ${ }^{a}$

\section{Resumo}

Nas poucas vezes em que apareceu o " am ha'aretz" (2 Ki. 11:14 BHT)" (povo da terra) em Esdras, houve uma autodenúncia dos elaboradores da redação final: eles desprezaram os estrangeiros, as mulheres e seus filhinhos. Os israelitas/hebreus que não foram exilados, por quase cem anos, conviveram com estrangeiros e tiveram abertura de gênero para os povos dos arredores. Com o apoio financeiro e político da Pérsia (Esd 7,18-25), os repatriados (Golah) deram o "golpe" no 'am ha'aretz. Chegaram com o projeto de reconstruir o Templo, de redefinir a religião baseada na "pureza" e reelaborar as diretrizes para o novo povo, agora chamado de povo "judeu". O/a leitor/a atento, hoje, tem lido esses vários textos com "suspeição" e, nessa desconfiança tem procurado a voz dos silenciados, a vez dos desaparecidos do sistema e o "espaço" conseguido pelos pobres e marginalizados. O livro de Rute será lido em total contraposição a Esdras (Esd 9-10). Com essa leitura se aprofundará o encontro com Yahweh, o Deus que está do lado dos pobres e desprezados. É preciso olhar, ainda, com suspeição a glosa em Rute (Rt 4,17d-22): acréscimo do poder para manipular todo o texto e toda a história libertadora.

Palavras-chave: Rute. Esdras 9-10. Povo da terra. Repatriados.

\footnotetext{
a Pontifícia Universidade Católica de Goiás (PUC Goiás), Goiânia, GO, Brasil. Pós Doutor e Doutor em Ciências da Religião, e-mail: joelantonioferreira@hotmail.com
} 


\section{Abstract}

On the few occasions when the "am ha'aretz" (people of the land) appeared in Ezra, there was a self-denunciation of the makers of the final writing: they despised strangers, women, and their little children. The Israelites / Hebrews who had not been exiled for nearly a hundred years, lived with strangers and had gendered openness to the surrounding peoples. With financial and political support from Persia (Esd 7, 18-25), the returnees (Golah) gave the 'blow' to the 'am ha'aretz. They arrived with the project to rebuild the Temple, to redefine the religion based on 'purity' and to rework the guidelines for the new people, now called the 'Jewish' people. Today's reader, by the Sociological Method with its Conflict/Contradiction/Dialectic model, has been reading these various texts with 'suspicion'. In this 'distrust' he has sought the 'voice' of the silenced, the 'time' of the disappeared system and the 'space' achieved by the poor and marginalized. Ruth's booklet will be read in complete opposition to Ezra (Ezra 9-10). With this reading will deepen the encounter with Yahweh, the God who is on the side of the poor and despised. One should also look with suspicion at the gloss in Ruth (Rt 4, 17d-22): an increase in power to manipulate the whole text and all liberating history.

Keywords: Ruth. Ezra 9-10. People of the land. Repatriated.

\section{Introdução}

Ao se buscar um modelo de leitura bíblica que ajude na opção preferencial pelos pobres, apresenta-se, aqui, a leitura sociológica pelo modelo conflitual/dialético/contradição ${ }^{1}$. Essa leitura começou na Escola de Chicago, noventa anos atrás e foi aprofundada com Bruce Malina (1981)2.

Ianni (2004), Fernandes (1980) e Maduro (1983) explicitaram a “vocação crítica” diante da sociedade assimétrica. Esses sociólogos do modelo conflitual da margem provenientes dos países pobres ajudaram nos

\footnotetext{
${ }^{1}$ É possível fazer essa leitura pela sociologia positivista (Simon e Comte), bem como pela sociologia funcionalista da ordem (Durkheim), pela sociologia organicista (Spencer) e outras. Porém, por essas correntes não se encontra o pobre. Privilegia-se o poder e a ordem (COSTA; SANTOS, 2002, 18-19). A leitura conflitual/dialética/contradição é um enfoque sociológico que parte dos conflitos sociais (OSIEK, 1989, p. 272), visando a mudança o elemento transformador da vida social.

${ }^{2}$ Baseia-se, aqui, em OSIEK (1989, p. 260-278) e ALVAREZ-VERDES (1989, p. 5-41).
} 
questionamentos das dominações imperialistas que submetem os povos que sobrevivem na submissão ao poder estrangeiro (FERNANDES, 1980).

Essa leitura conflitual lê a Bíblia a partir dos pequenos e marginalizados e não a partir do oficial. Procura olhar as assimetrias fortes em toda a Bíblia e, com isso, lê os textos com suspeição e com desconfiança (FERREIRA, 2011, p. 52). Essa leitura procura “desconstruir-construir" um texto, uma perícope a fim de resgatar as pessoas, os grupos sociais que foram manipulados pelo sistema dominador. Aí se define o "lugar social" dentro dos textos para ouvir o grito dos marginalizados e denunciar a voz dos que detêm o poder. Esses precisam ser os "protagonistas" do texto.

Essa busca quer ler uma marginalizada estrangeira, viúva e pobre: Rute. O seu testemunho, com o apoio de Noemi e das mulheres de Belém, foi tão significativo que se tornou um texto do cânon bíblico. Essa investigação quer ler, também, Esdras (Esd 9-10) que, ao contrário, foi o tipo do opressor contra os étnicos, as mulheres estrangeiras e suas crianças. O seu texto, igualmente, foi sacramentado e está no cânon bíblico.

\section{Rute}

Para se compreender esse livreto, é preciso situá-lo no contexto da política internacional (Pérsia) e do novo povo judeu liderado por Esdras.

\subsection{Leitura de Esdras (Esd 9-10), na ótica da opção pelos pobres}

Após o cativeiro da Babilônia (586-538), quando a Pérsia ocupou o senhorio do mundo da época e autorizou que os descendentes da antiga elite de Israel retornassem às suas terras (Judá), agora com prestígio e autoridade, esse grupo da Golah em 458 aC, com um mil e setecentas pessoas reapoderouse dos arredores de Jerusalém. Com a jurisdição reconhecida pelo rei da Pérsia e com seu apoio econômico e político a Golah chegou com o grande projeto de reconstruir o Templo e redefinir as diretrizes para o novo povo, agora chamado de povo “judeu”. Quem ficou à frente foi o grupo sacerdotal.

O grande problema foi que, ao retornarem, encontraram a antiga terra habitada pelo "povo da terra” ( 'am ha'aretz): sem a intolerância dos antigos dominadores de Judá e Jerusalém, aquele povo, tranquilamente, absorveu 
outras etnias e teve abertura de gênero para os povos dos arredores (Esd 9, 1: moabitas, amonitas, cananeus, egípcios, amorreus, jebuseus, ferezeus, heteus etc). A camaradagem entre os israelitas/hebreus com os estrangeiros era interessante e tranquila.

Os que retornaram (Golah) ficaram aturdidos com as experiências de abertura dos antigos israelitas/hebreus que ficaram na terra, na convivência pacífica e afetiva com os estrangeiros. De vários matrimônios entre israelitas e estrangeiras, nasceram muitas criancinhas.

Em nome de Yaweh, os membros da Golah tomaram atitudes enérgicas contra o "povo da terra" e seus amigos étnicos. Criou-se a ideologia da intransigência contra os estrangeiros, contra as mulheres e contra seus filhos nascidos de pais estrangeiros. Nessa ideologia da incomplacência, a partir do livro de Esdras (Esd 9-10), pode-se ver, com evidência, a tomada do poder do grupo sacerdotal, a discriminação do "povo da terra” ('am ha'aretz) e a rejeição total dos estrangeiros.

Dois nomes são referenciais nesse novo projeto da Golah: Sequenias, uma espécie de mentor intelectual da nova ideologia (Esd 10,2) e o sacerdote Esdras, o homem forte do novo movimento restaurador. Sequenias foi quem detectou a "adversidade horrorosa" entre os antigos hebreus, os que ficaram na terra: a "população local” (Esd 10,2) estava se casando com "mulheres estrangeiras". Com o susto de Esdras, ele fez uma proposta trágica, vergonhosa, aética e antiética: "Nós nos comprometemos a despedir 'todas as mulheres estrangeiras' e os 'filhos' que tivemos com elas" (Esd 10,3). Foi teatral a postura de Esdras: após os relatos dos "chefes" (Esd 9,1-2) ele rasgou as roupas, o manto e arrancou os cabelos da cabeça e da barba e, desolado, caiu de joelhos e levantou as mãos a Javé (Esd 9,3-5), fazendo uma longa oração (Es 9,6-15) de confissão e com choro (Esd 10,1). Estavam arrependidos (Esd 10,2).

Os "exilados" agora repatriados (Esd 10,7-8) se separaram, absolutamente, das "mulheres estrangeiras" (Esd 10,3.11) e dos seus "filhinhos" (Esd 10,3), bem como do "povo da terra" porque esse era "sujo" (Esd 9,11). Criou-se a ideologia da "pureza" (Esd 9-10) como base da organização judaica. Para salvar Jerusalém e o novo Templo, bem como suas 
muralhas, a "raça santa" (Esd 9,2) precisava ser "separada". Não se devia falar mais em "povo hebreu”, mas “judeu”. Com isso, o projeto apresentou várias tendências arbitrárias e segregacionistas: pedofobia, etnocentrismo, racismo, xenofobia, misoginia. Tudo para amparar os repatriados do cativeiro da Babilônia.

Revelou-se agora, no tempo de Esdras, ao receber o apoio de todos os repatriados (Esd 10,5) que esses eram das tribos de Benjamim e Judá (Esd 10,9). E os antigos descendentes das outras dez tribos? Eram todos 'am ha'aretz? Eram, agora, judeus de categoria inferior? Surge com a nomenclatura nova "povo judeu", uma clara assimetria ideológica e social que gerou consequências fortes e injustiças indefiníveis. Essa nova tendência apoiada pela Pérsia foi que criou a intolerância contra o gênero feminino e contra as crianças (Esd 10,10-12) 3 . Segundo o redator, por "vontade de Deus". Concluindo, jogaram toda a responsabilidade racista e xenófoba para Deus (Esd 10,14). Quando encerraram as expulsões (Esd 10,16-17), ofereceram carneiros ao Senhor, como se se negociasse com Deus as atitudes antiéticas (Esd 10,19). O livro apresentou, a seguir, a lista dos novos "puros" de Judá e Benjamim (Esd 10,18-44).

\subsubsection{Esdras 9 e 10: A lei da pureza foi muito dura com os pobres ${ }^{4}$}

Houve o apoio financeiro e político da Pérsia (Esd 7,18-25). Os repatriados (Golah) dão o golpe naqueles que permaneceram sempre em Israel, ou seja, o ‘am ha'aretz. A religião baseada na "pureza” foi imposta e, com isso, desnorteou o "povo da terra".

\footnotetext{
3 É preciso chamar a atenção do/a leitor/a para o seguinte: De fato, o texto de Esdras 9-10 é agressivo e expressou uma ideologia/teologia insustentável. Porém, não se pode confundir a postura de Esdras e seu grupo com o "judaísmo". Embora Esdras esteja na ponta da criação do "judaísmo" pós exílico, essa religião sempre foi uma das forças religiosas e presentes na história e, hoje, é bem representada no diálogo inter-religioso mundial.

${ }^{4}$ Cf. FERREIRA; MARQUES, 2019, p. 169-185. Na Revista Interações (Cf. 2019, p. 177-9) Ferreira e Marques apresentam algumas dessas denúncias. Aqui elas são ampliadas.
} 
Definiu-se a "pureza" judaica. Esta cegou Esdras e seu grupo. Desapareceu a misericórdia. O programa da raça sem estrangeiros (nação santa) criou a intolerância.

Ao apontar a "vontade de Deus" (Esd 10,11) reflete-se a imposição da lei da pureza contra o povo da terra. Em nome dessa lei, foram dizimadas muitas famílias, destroçadas as crianças, esmagadas as mulheres estrangeiras, sendo, por isso, a xenofobia apoiada oficialmente.

Agora, o monoteísmo aberto da linha isaiana perdeu o lugar para o monoteísmo enclausurante dos repatriados (Golah).

Usou-se a "liturgia espetáculo" para comover a plateia (Esd 10,14-17) e para tentar a complacência de Deus a favor dos detentores do poder.

Sequenias, Esdras e seu grupo usaram o nome de Deus em vão, apresentando um deus intolerante e discriminador.

O Deus da Bíblia foi vilipendiado em Esdras (Esd 9-10). O Deus que fez, historicamente, a opção preferencial pelos pobres, no livro de Esdras, parece, foi deslocado para os ricos e poderosos que vieram com todo o apoio da Pérsia e fizeram dele um comerciante a favor dos repatriados (Golah).

O “deus" de Esdras não gostava das criancinhas e de suas mães, isto é, estrangeiras e seus filhos não eram filhos de Deus. As anomalias psíquicas das lideranças dos repatriados eram deslocadas para Deus.

Houve um holocausto afetivo, psíquico e ideológico contra as criancinhas e suas mamães estrangeiras.

Sobre os filhinhos de mães estrangeiras (Esd 10,3): jogados na rudez da lei da pureza, como, um dia, aquelas crianças iriam entender a linguagem do amor e da ternura?

Que grupo comunitário foi aquele que, ao perder a sensibilidade humana, jogou as criancinhas às traças? O duro é saber que todas aquelas crianças tinham, também, o sangue dos hebreus. Mas, fora isso que já era trágico, qualquer criança não é, também, imagem e semelhança de Deus? (Gn 1,26-27).

É importante ressaltar que quatro pessoas não embarcaram no projeto de Esdras (Esd 10,15). E as outras dezenas e dezenas de pessoas? Quer dizer que todos os outros aderiram ao projeto xenófobo, misógino e racista de 
Esdras? O deus dessa legião de pessoas também o era? Os papais que aceitaram a imposição da lei perderam o amor pelos filhos e a afeição das suas esposas?

O “deus" dos sacerdotes esdrianos se nivelava por baixo, aceitando o sacrifício dos carneiros para reparar os pecados dos repatriados? A falta de amor sacerdotal aos pobres da terra levou a região de Jerusalém a uma hecatombe imposta aos marginalizados.

Existe um povo especial para Yahweh? Para os sacerdotes esdrianos é a "nação santa”, representada pelos repatriados da Babilônia. É um povo "puro" que deve ser seguido pelo "povo da terra".

A leitura sociológica conflitual/dialética/contradição, que lê a Bíblia a partir dos pobres e marginalizados, procurando ouvir a voz e descobrir os espaços desses desprezados, tem dificuldade em entender como os capítulos 9 e 10 de Esdras foram colocados no cânon bíblico. O Deus libertador que se manifestou, em primeiro lugar, no livro do Êxodo, ao contrário, aqui em Esdras torna-se um carrasco. O grupo sacerdotal o transformou num "deus sectário". Esses capítulos não têm proximidades em outros textos bíblicos. Esdras 9 e 10 são pedófobos, etnocentrista, xenófobos e racistas.

Se Esdras e seu grupo pensaram que podiam criar uma nova sociedade judaica por meio de leis e decretos impostos de cima para baixo, sem a participação dos 'am ha'aretz (povo da terra), se quiseram impor o desrespeito, a falta de ética e a total desumanização da "nova" nação, naquele mesmo momento, houve a reação de quem estava no "lugar social" dos marginalizados. Surgiram os livros dos Cânticos dos Cânticos, Jonas e Rute como resistência aos sacerdotes de Jerusalém. Olhar-se-á, então, um desses livros, o de Rute: é o retrato de quem estava sofrendo todo tipo de marginalização e que, no entanto, pela fé em Yahweh, resistiu porque nunca perdeu a esperança. 


\subsection{Leitura de Rute, na ótica da opção pelos pobres}

Aqui, parece, surgiu um problema muito sério. O livro de Rute era lido e querido pelas comunidades simples do campo e do interior. O livro queria apresentar um projeto dos pequenos camponeses e moradores do interior. No entanto, as forças de Jerusalém, incomodadas com o texto e vendo que ele penetrara nas camadas simples, para aprová-lo, fez algumas interferências indébitas.

\subsubsection{Rute foi do tempo dos Juizes ou de Esdras?}

O texto foi elaborado como se tratasse do tempo dos Juízes (após Moisés até Samuel). É provável ser um artifício dos/as autores/as finais (SILVA, 2008, p. 107-120) para retratar o tempo em que estavam vivendo (LAFFEY, 2007, p. 1087). Era, possivelmente, o tempo de Esdras (458 a.C.) ao de Neemias (445 a.C.).

O livro de Esdras, particularmente, dois capítulos (Esd 9-10), é a expressão de um regime opressor e repressor que entrou no cânon da Bíblia. O livro de Rute, expressão de experiências libertadoras e, com isso, uma forte resistência e crítica ao grupo de Esdras, também entrou no cânon da Bíblia. Se o grupo de Jerusalém controlava a ideologia, a teologia e a literatura, como explicar a presença do livro de Rute?

Parece que a chave da resposta está no início (Rt 1,1) e, principalmente, no final do livro de Rute (4,18-22). Ali tem uma tōləọah (= genealogia). Essa estava no original do livro de Rute ou foi uma glosa (acréscimo) feita pelos sacerdotes do grupo de Esdras?

1.2.1.1. Uma glosa perigosa vinda do centro do poder

\footnotetext{
5 Também aqui, Ferreira; Marques (2019, p. 178-183) apresentaram, com outras roupagens, a resistência de Rute, do grupo feminino e de Boás à repressão dos poderosos de Jerusalém, liderados por Esdras.
} 
É preciso averiguar dois aspectos para se entender essa provável glosa (FERREIRA; MARQUES, 2019, p. 169-185) acrescentada pelos redatores de Jerusalém, ligados ao grupo de Esdras.

a) Aspecto exegético: final do livro de Rute (Rt 4,13-17c): Olhando pela exegese, está claro que o livro original de Rute terminou em 4,13-17c onde se vê a expressão da voz e espaço das mulheres na compreensão dos acontecimentos maravilhosos iluminados por Deus. É preciso ficar atento para duas expressões:

wattêled bên (conceber/dar à luz a um filho): a, v. 13; a', v. 16

yullad-bên (nasceu-lhe um filho): b, vv. 14-15; b', v. 17a-c

É preciso, no aspecto exegético, chamar a atenção para bên (filho). Seu nome foi Obed (o que serve). Isso para se entender a distância entre a "lei da pureza" que expulsava os filhos de estrangeiras e a "lei do amor" vivenciada por Rute e Boás (Rute era mulher e estrangeira e Boás era israelita). A exegese nos ajuda a entender que nessa lei, o serviço deve estar na vida de todos. Obed sintetizou a vitória das crianças marginalizadas sobre a lei da pureza.

Antes de olhar a organização do texto num quadro (FERREIRA; MARQUES) ${ }^{6}$, é preciso averiguar alguns detalhes significativos, que mostram essa organização:

Os vv. 14-15 expressam, em discurso, as ações femininas;

Os vv. 17a-c, "dar o nome ao filho" mostram as mulheres ocupando os seus espaços e soltando a voz.

Quando se olham os v. 13a-e (todas as cinco partes do versículo) e os v. $16 a-c$ veem-se os claros paralelismos sinonímicos da construção com uma lógica interna e conclusiva dessa pequena rede comunicativa, tanto na forma como no conteúdo. Há uma estrutura sintática idêntica usando o verbo "tomar" (läqah), nos vv. 13a, 16a, e a expressão "e ela se tornou para ele [...]" (wattəhî lō lə): "Ela se tornou para ele esposa" (v. 13b); "Ela se tornou para ele uma cuidadora" (v. 16c). Eis a organização textual:

\footnotetext{
6 Procurou-se fazer uma tradução literal do texto para possibilitar uma visualização melhor das principais sentenças idênticas repetidas e o quadro foi mantido in ipsis litteris.
} 
Quadro 1 - De uma estrangeira e de um israelita nasce o Goel

\begin{tabular}{|c|c|}
\hline A: v. 13 & $\begin{array}{l}\text { E tomou (wayyiqqah) Boás a Rute, e ela tornou-se } \\
\text { para ele (wattəhî lō lə) mulher; coabitou com ela, e } \\
\text { o Senhor lhe concedeu a concepção, e ela } \\
\text { concebeu um filho. }\end{array}$ \\
\hline B: vv. 14-15 & $\begin{array}{l}\text { E disseram as mulheres (hannāšîm) a Noemi: Seja o } \\
\text { Senhor bendito, que não deixou, hoje, de te dar um } \\
\text { goel, e será aclamado o nome dele (wəyiqqārê šəmō) } \\
\text { em Israel. Ele será restaurador da tua vida e } \\
\text { consolador da tua velhice, pois tua nora, que te ama, } \\
\text { o deu à luz, e ela te é melhor do que sete filhos. }\end{array}$ \\
\hline$A^{\prime}:$ v. 16 & $\begin{array}{l}\text { E tomou (wattiqqah) Noemi o menino, e o pôs no } \\
\text { regaço, e ela se tornou para ele (wattəhî lō lə) uma } \\
\text { guardiã. }\end{array}$ \\
\hline$B^{\prime}:$ v.17a-c & $\begin{array}{l}\text { E deram-lhe as vizinhas (haššəkênōt) um nome, } \\
\text { dizendo: À Noemi nasceu um filho. E lhe chamaram o } \\
\text { nome dele (wattiqrenāh šəmō) Obed. }\end{array}$ \\
\hline
\end{tabular}

\section{a) A Glosa (Rt 4,17d-22) muda tudo:}

Ainda dentro do aspecto exegético, é necessário chamar a atenção para alguns detalhes acrescentados pelos redatores finais desses acréscimos7: já no v. 17d onde se escreveu que “Este é o pai de Jessé, pai de Davi”, já deixa o/a leitor/a com desconfiança. Se os versículos anteriores (13-17c) mostraram a festa das mulheres diante dos acontecimentos maravilhosos de Deus, este v. 17d já denunciou que essa afirmativa já não era do grupo feminino, mas, possivelmente, de algum masculino ligado a Jerusalém. O que teria a ver Obed, nominado pelas exuberantes mulheres, com Jessé e Davi? Isso, no livro de Rute? Obed foi fruto do amor dos marginalizados em Rute. O Obed da glosa pertence ao poder.

Outra "suspeição": a genealogia (4,18-22). Inicia-se, com evidência, o gênero literário "genealogia", típico das fórmulas do Pentateuco ("e estas são as gerações de [...]" (wə'êlleh tōlədōot) para falar, genealogicamente, de um descendente (Gn 6,9; 10,1; 11,1; Nm 3,1). Também, lembra o livro de Crônicas

\footnotetext{
${ }^{7}$ Além da terrível glosa (acréscimo) colocado no final do livro (Rt 4,17d-22), os especialistas chamam a atenção para o início do livro (Rt 1,1 ), dizendo que os redatores finais também impuseram a expressão "no tempo em que os juízes governavam...", para ligar ao final do livro e deixar o/a leitor/a convicto de que o livro de Rute retratava o tempo dos juízes.
} 
(1Cr 2,2-15) (CAMPBELL, 1975, p. 170), que mostra a estranheza genealógica no final do livro de Rute. Olhando pelo nível exegético, vê-se uma interferência indébita no final do livro.

\section{b) Aspectos teológicos e ideológicos do livro de Rute:}

As genealogias eram expressões dos grupos sacerdotais ligados à cidade de Jerusalém. A "tradição sacerdotal” foi uma marca significativa dessa cidade, por séculos (WILSON, 1975, p. 169-189; WILSON, 1977; JOHNSON, 1998, p. 3-36; LEVIN, 2001, p. 11-46). Ora, no livro de Rute, aparece uma genealogia que denota uma total falta de sintonia com a teologia de Rute. O grupo sacerdotal, a partir de Esdras, preocupou-se, em nível teológico, com a “pureza” étnica dos judeus. Esse conceito destoa-se, completamente, com a preocupação do grupo de Noemi, Boás, Rute e as mulheres. Ao contrário da pureza massacradora esdriana, o grupo dos pobres estava vivenciando o encontro das etnias (hebreus/israelitas e estrangeiros) e a abertura de gênero tão avesso aos sacerdotes de Jerusalém.

Se as genealogias se preocuparam tanto com a dignidade hereditária, o texto de Rute desconhece, absolutamente, esse histórico. A mulher Rute era estrangeira. Nunca se preocupou com sua história genealógica. Ao contrário, quando fez a aliança com Noemi, o seu povo e seu Deus, ela deu um salto para as consequências da aliança: abertura dos pobres para com os pobres e a compreensão viva e dinâmica do universo de gênero. Se, teologicamente, o grupo de Esdras não se interessava pelos pobres como senhores de sua história, a visão teológica do grupo de Rute foi dar segurança àqueles mesmos marginalizados: realizando as leis da "respiga", do "levirato" e do "resgate", uma comunidade mostrou o seu rosto comunitário para o desinteresse de Jerusalém.

Se as genealogias queriam legitimar os papéis jurídicos, políticos e religiosos, o livro de Rute, até o final originário (Rt 4,13-17C) não tem o mínimo dessas preocupações (FLANAGAN, 1981, p. 58-65). Olhando pela intenção teológica, a partir do grupo esdriano, a genealogia acrescentada no final do livro de Rute (Rt 4,17d-22) está totalmente estranha ao texto original (CAMPBELL, p. 1975, p. 15). É uma interferência indébita e pedante. 
O livro de Esdras foi escrito pelos escribas e sacerdotes de Jerusalém. $O$ livro de Rute, sem os "acréscimos" (Rt 1,1 e Rt 4,17d-22), surgiu na periferia, possivelmente, entre os marginalizados da região de Belém, ou seja, fora dos domínios sacerdotais. Vê-se que os marginalizados, quando se conhecem e se encontram, determinam o seu "lugar social" explicitando a sua voz e o seu espaço (FERREIRA, 2011, p. 48-52). Diante disso, é preciso perceber a desfaçatez do grupo de Jerusalém em colocar uma glosa tão ridícula que quase estragou as intenções do livro de Rute. Aliás, por séculos e séculos a ideologia da genealogia (Rt 4,17d-2,2) matou as intenções libertadoras do livro. O livro de Rute, por séculos e séculos, tornou-se um livro "edificante" e bonito que não levava, jamais, ao desafio de animar os pobres e marginalizados. Faz bem pouco (década de 1980 para cá) que se redescobriram os objetivos transformadores desse livro.

Recordando, os repatriados (o grupo da Golah) impuseram-se ao povo da terra ('am ha'aretz). Os detentores do poder forçaram a "lei da pureza" a todo/as, inclusive, aos pobrezinhos. Agora, como, conhecendo a literatura de Rute, aquele grupo até a aprovação da redação final, iria colocar no "cânon das escrituras" um livro que era o retrato da resistência aos esdrianos? Foi aí que tiveram a ideia brilhante e audaciosa: se o livro era conhecido de todos e aceito, então, era necessário fazer duas glosas (acréscimos) que mudassem tudo: apareceram, na redação final, o início (Rt 1,1) e a genealogia (Rt 4,17d-22).

Em Rute (Rt 1,1) surge, no início, uma glosa: "no tempo em que os Juízes governavam...". Com a tölədah (= genealogia) os/as leitores/as foram transportados para o tempo dos Juízes. Com isso, as mulheres (Noemi, Rute e as mulheres de Belém) foram apagadas na genealogia. A força da presença da estrangeira (Rute) foi, também, extinta. A genealogia apagou com os nomes de Elimeleque e Quélion (Rt 1,2), desfazendo-se da vitória social do levirato que aparece no livro. Se a genealogia (Rt 4,17d-22) termina em Davi, agora, legitimou-se o contrário da proposta de abertura do livro de Rute que era a inclusão dos estrangeiros. Davi, como rei, excluiu todos os estrangeiros (2 Sm 8). Para o grupo de Esdras, ou após ele, estava consumada a eliminação dos estrangeiros da terra dos agora chamados "judeus". 
1.2.2. Vizualizando a narrativa

Noemi (hebreia que foi morar no estrangeiro) e as duas noras Orfa e Rute (estrangeiras) tornaram-se três viúvas. Aqui se vê, nas entrelinhas, que a palavra "estrangeiras" já apontou para o sistema esdriano da exclusão dos étnico/as. Possivelmente, era o tempo de Esdras (458 a.C) ao de Neemias (445 a.C), quase um século após a libertação do cativeiro da Babilônia.

O livro de Rute é o espelho da terra ocupada pelos 'am ha'aretz (povo da terra) e por estrangeiros, que ali conviviam bem, após o exílio da Babilônia. No entanto, era uma região cheia de problemas como a falta de terra ( $\mathrm{Ne} 5,5)$, a fome (Rt 1,1), a migração (Rt 1,1), a morte (Rt 1,3.5). A família de Noemi e Elimileque, junto aos filhos Maalon e Quelion, ao migrarem para Moab, continuou a ter problemas de sobrevivência. Após casar-se com estrangeiras, o pai e os filhos morreram no exterior.

Com muitas reflexões e tensões, a hebreia Noemi retorna a Israel junto a uma estrangeira Rute: se Esdras expulsava, as mulheres retornavam. Chegando a Belém (casa do pão), Noemi é reconhecida pelas mulheres (Rt 1,19). Essas se alvoraçaram de alegria, porque, ao contrário da expulsão, duas estão retornando. Noemi se define como "Mara". Todas as mulheres no tempo de Esdras eram amarguradas. Noemi era o retrato da desolação.

1.2.3. A recuperação das leis da respiga, do levirato e do resgate que reanimarão a convivência dos pobres

Depois da tempestade vem a bonança. Nas roças de Belém começavam as colheitas. Um tempo de abundância. Rute que havia, tenazmente, decidido ficar ao lado da sogra Noemi, aderido ao seu povo e ao seu Deus (Rt 1,16-17), que fez a aliança com a sogra e aos marginalizados da terra ("seu povo será o meu povo"), mostrou seu vigor e fibra de mulher, de viúva, de estrangeira e de pobre: ao contrário das leis de Esdras, Rute quer salvar sua sogra Noemi e a si mesma, para iniciar um novo tipo de vida, totalmente diferente do projeto esdriano. Sabendo da "lei da respiga" foi à roça para catar os restolhos de espigas. Esses eram dos pobres, estrangeiros, órfãos e viúvas (Lv 19,9-10; Dt 
24,19). Aqui, quem redigiu o livro de Rute aproveitou-se da tradição dos Juízes para questionar o sistema fechado do grupo de Jerusalém.

Apareceu a figura de Boás (Rt 2,3), dono das roças de cevada ${ }^{8}$. Nesses campos, a estrangeira Rute realizou a "lei da respiga". Boás se maravilhou da grandeza da moabita Rute e a agregou às colheitas e à participação de outras trabalhadoras (Rt 2,4-14). Boás, ao contrário de Esdras, dialogou com uma mulher que era estrangeira. Falou-lhe ao coração e se referiu a Deus (Rt 2,1112), com afeição.

Além da lei da respiga, apareceram a "lei do resgate" (Rt 3,9-13) e a "lei do levirato" (Dt 25,5-10). Com as três leis, criticam-se as posturas de Esdras que expulsara as mulheres estrangeiras. Ao contrário, a apresentação das três leis em Rute explicita o amor e a união entre o israelita Boás e a estrangeira Rute. Começava a acontecer a reconstrução comunitária, de baixo para cima. As três janelas estavam acenando para o amor: todos deveriam ter pão em abundância.

O israelita Boás, pela "respiga", alimentou os pobrezinhos na colheita e, também, a estrangeira Rute, bem como a amargurada Noemi. Pelo "resgate", ficou sem quase nada. Pela lei do "levirato", não será pai do primeiro filho que vier. Quer dizer que Boás se esvaziou de tudo, por causa das leis antigas? As dez testemunhas, quando presenciaram o primo mais próximo recusando-se a assumir essas leis (Rt 4,1: ele era como Esdras) e ao testemunharem o segundo primo, Boás, a assumir aquelas mesmas leis, declararam, com vigor: "E você, Boás, seja poderoso em Éfrata e tenha nome em Belém. Pelos filhos que Deus Ihe der com esta jovem, sua família seja tão abençoada como a de Farés, que Tamar deu à luz para Judá" (Rt 4,12). As dez testemunhas compreenderam que Boás falou ao coração de Rute (Rt 2,13-14). Entenderam que amor não é propriedade de nenhuma etnia, muito menos dos poderosos de Jerusalém. $O$ forte nessa proclamação das dez testemunhas é o grito "pelos filhos que Deus Ihe der com

\footnotetext{
8 Boás, no livro de Rute, é o contrário de Esdras. Como diz Mesters (1985, p. 49) Ele é como um juiz esperado. Lembra a ação de Javé, o Deus do povo. Através de Boás, Deus vai salvar os pobres. Vai dar pão, garantir a posse da terra, vai gerar um filho. Ele lembra os Juízes Gedeão e Jefté, porque é definido como homem forte e de grande valor.
} 
esta jovem [...]". É a resposta dos pobres ao desumanismo do grupo de Esdras que expulsava, também, as criancinhas de Israel (Esd 10,3).

Juntando as três leis, na prática, fruto do encontro de Noemi, Rute e Boás, a defesa dos pobres foi se expandindo e saltando da visão da "pequena família" para a "grande família" (clã e comunidade), tomando uma visão social maior e comprometedora. As três leis que pareciam estar nas cinzas, agora, de novo, tornaram-se dinâmicas.

O livro de Rute surgiu na mentalidade do II Isaías (Is 49,6), quando, no exílio, anunciou que a "minha salvação chegue até os confins da terra". Aqui, o livro de Rute está, quase cem anos após o exílio, concretizando, no encontro de Noemi, Rute e Boás, que Yahweh é o Deus de todas as etnias. Noemi, naquela visão, sendo uma participante do 'am ha'aretz (povo da terra), trouxe para esse grupo a estrangeira Rute, promoveu o matrimônio da moabita com o israelita Boás, estimulou a salvação para os étnicos e, ao mesmo tempo, apontou as feridas profundas do projeto esdriano contra os estrangeiros e as dez tribos do norte de Israel. Noemi agiu como uma profetisa.

Quem redigiu o livro de Rute fê-lo a partir dos olhos de quem estava lá embaixo. Eram os marginalizados os que foram descobrindo o novo caminho. Perceberam que a lei da migração de Esdras era descabível e desumanizante. Era a lei, em nome da "pureza", xenófoba. A nova lei, descoberta pelos pobres era a lei do amor que não olhava a etnia, a cultura, a religião. Via o ser humano. O redator do livro entendeu que Rute era querida de Deus, porque muito amou.

Ela amou Noemi, amou Boás. Unindo-se a este israelita, a estrangeira Rute via mais longe a figura do herdeiro: totalmente, o contrário do grupo de Esdras (Esd 10,3) que expulsara, também, as criancinhas. Ela via a herança e um novo futuro de liberdade e de vida, não só para a família, mas para a comunidade maior.

Se o leitor desavisado se assusta com as perícopes de Esdras (Esd 9-10), elaborado pelos grupos de escribas ligados à classe sacerdotal de Jerusalém, por outro lado, tem o conforto de ler o pequeno livro de Rute que mostrou que as amarguradas (Noemi), as segregadas (Rute), as eliminadas (criancinhas e estrangeiras) e os receptivos (Boás) foram aqueles que, em comunidade dos 
pobres, efetivaram a vida buscando espaço e fazendo ouvir suas vozes, e, assim, esse livro mostrou o verdadeiro rosto da Sagrada Escritura: Deus está do lado dos marginalizados, sempre. Essa preferência de Deus foi registrada pelo evangelista Mateus ( $M t$ 1,5) ao colocar a estrangeira Rute e o israelita Boás na ascendência de Jesus $^{9}$. O interessante é que, na tradição judaica posterior, não se conhece qualquer alusão a Esdras e seu grupo impostor e desumano, em futuros textos bíblicos.

\section{Conclusão provisória: Deus do lado dos desprezados}

Diante da glosa que quis mudar tudo (Rt 4,17d-22), a preferência de Yahweh foi pelos detentores do poder (Esd 9-10) ou pelos humilhados (Rute)? O grupo sacerdotal, quando foi fazer a grande obra das redações finais, conhecia e ouvia como o texto de Rute era tão popular. Aqueles redatores, além da fé em Yahweh, por muitos momentos, deixou-se levar pela ideologia do poder e da pureza. Isso aconteceu com vários salmos e, também, até com textos proféticos e outros. Existiram inumeráveis glosas na Escritura Sagrada.

A história de Rute incomodava. Era um relato crítico. As narrativas de sua história eram de denúncia. Era, no entanto, um texto querido. Era preciso legalizar o livro, mas, alterando o princípio (Rt 1,1) e o fim (Rt 4,17d-22). Assim, a obra agradaria a todos. Foi, possivelmente, esse o objetivo dos redatores finais. Ao acrescentar, especialmente o final do livro, o grupo sacerdotal fez uma leitura historicizante: não dialogou com as camadas marginalizadas e desviou a narrativa que o povo contava por vários séculos atrás. Isto é, o passado hebreu teve muitos percalços na observância da Tora e a monarquia precisava ser preparada dentro dos moldes da observância da "lei de Deus". Acrescentando o início ("No tempo em que os Juízes governavam": Rt 1,1) e o fim ("Obed foi o pai de Jessé e Jessé foi pai de Davi": Rt 4,17d), os redatores desviaram a história para os tempos dos Juízes. Assim, acharam que estavam

\footnotetext{
9 Mateus, que nunca foi do 'grupo sacerdotal', mais tarde, ao colocar o nome de Rute na Genealogia de Jesus (Mt 1,5b), estava sugerindo que Jesus veio, também, dos estrangeiros. A estrangeira Rute foi, também, ascendente do Messias.
} 
preparando a monarquia de Davi e, também, salvando o sistema opressor, racista, xenófobo, pedófobo e etnocêntrico do grupo sacerdotal esdriano.

Porém, o pessoal da periferia, da margem, do campo não engoliu a tramoia dos detentores do poder. Continuaram a contar a história de Noemi, Rute, as outras mulheres e Boás na perspectiva original e transformadora. Para os pobres, o encontro dos hebreus e estrangeiros, naquele tempo, era questão de honra. Para aquele grupo, o encontro de gênero era movido pelo amor. Para aqueles/as marginalizados/as o ato de fé de Rute representava a história dos/as estrangeiros/as: “[...] aonde você for, eu também irei. Onde você viver, eu também viverei. Seu povo será o meu povo e seu Deus será o meu Deus. Onde você morrer, eu também morrerei e serei sepultada [...] (Rt 1,16-17a). O grito dos pobres não veio de Jerusalém, mas de Belém (Rt 1,19 e 22). Esse grito (Noemi muda o seu nome para amargurada: Rt 1,20-21) foi pela sobrevivência comunitária, a partir da luta pelos próprios direitos e a defesa da justiça (respiga, levirato e resgate). Conquistando os direitos, o grupo viveu, intensamente, a partilha e o amor. A partir de cada conquista, amadureceu a esperança que culminou na vida, provinda de Rute e Boás (Rt 4,13). O nome foi dado pelas vizinhas (a força comunitária das mulheres): Obed (Rt 4,17c), aquele que "serve". Agora, com a vida explicitada, a história não era controlada por Esdras, mas pelos pobres que tinham a história na mão, porque Yahweh estava com eles (Rt 4,12.13).

\section{Referências}

ALVAREZ-VERDES. El método sociológico en la investigación bíblica actual. St. Mor, $\mathrm{n}$. 27, p. 5-41, 1989.

CAMPBELL, E. F. Ruth. A New Translation with Introduction, Notes and Commentary. New York: Doubleday, 1975. (Anchor Bible Commentary, 7).

COSTA, S; SANTOS, N. Positivismo e República: concepções e formação do Estado brasileiro. Goiânia: Ed. da UCG, 2004.

SILVA, A. J da. Estudos Bíblicos, 98. Petrópolis: Vozes, p. 107-120, 2008.

FLANAGAN, J. W. Chiefs in Israel. The Journal for the Study of the Old Testament, v. 20, p. 47-73, 1981. 
FERNANDES, F. A Natureza Sociológica da Sociologia. São Paulo: Ed. Ática, 1980.

FERREIRA, J A. Paulo, Jesus e os Marginalizados: Leitura Conflitual do Novo Testamento. Goiânia: Ed. da PUCGoiás, 2011.

FERREIRA, J. A.; MARQUES, M. de S. Rute: como permitiram a sua presença na Bíblia? Interações. Belo Horizonte: Ed. PUC Minas, v. 14, n. 25, p. 169-185, 2019.

IANNI, O. Florestan Fernandes: Sociologia Crítica e Militante. São Paulo: Expressão Popular, 2004.

JOHNSON, M. D. The Purpose of the Biblical Genealogies with a Special Reference to the Setting of the Genealogies of Jesus. Cambridge: University Press, 1998. (Studiorum Novi Testamenti Societas Monograph, 8).

LAFFEY, A. L. Rute. In: BROWN, R. E.; FITZMYER, J. A.; MURPHY, R. E. (Editores). Novo Comentário Bíblico S. Jerônimo: Antigo Testamento. Santo André/São Paulo: Academia Cristã/Paulus, 2007.

LEVIN, Y. Understanding Biblical Genealogies, Currents in Research. Biblical Studies 9, Sheffield: Sheffield Academic Press, p. 11-46, 2001.

MADURO, O. Religião e Luta de Classes. Petrópolis: Vozes, 1983.

MALINA, B. The New Testament World: Insights from Cultural Antrhropology. Atlanta: John Knox, 1981.

OSIEK, C. The New Handmaid: the Bible and the Social Sciences. TS, n. 50, p. 260-278, 1989.

WILSON, R. R. The Old Testament Genealogies in Recent Research. Journal of biblical Literature 94. Philadelphia \& Atlanta, p. 169-189, 1975.

WILSON, R. R. Genealogy and History in the Biblical World. New Haven: Yale University Press, 1977. (Yale Near Eastern Researches, 7). 